Comeal isolates from patients with microbial keratitis $(n=32)$

\begin{tabular}{|c|c|c|c|c|}
\hline & \multicolumn{3}{|c|}{ Patients wearing contact lenses } & \multirow{2}{*}{$\begin{array}{c}\text { Patients not } \\
\text { wearing } \\
\text { contact lenses }\end{array}$} \\
\hline . & Soft* & Hard $†$ & Therapeutic $\ddagger$ & \\
\hline \\
\hline Pure infections & & & & \\
\hline \multicolumn{5}{|l|}{ Gram negative } \\
\hline Other pseudomonas & & & & 2 \\
\hline Other & 1 & 2 & 1 & 4 \\
\hline $\begin{array}{l}\text { Gram positive } \\
\text { Mixed bacterial infections }\end{array}$ & & & 4 & 8 \\
\hline \multirow{2}{*}{\multicolumn{5}{|c|}{$\begin{array}{l}\text { Gram negative } \\
\text { Pseudomonas aeruginosa + Gram }\end{array}$}} \\
\hline & 1 & & & \\
\hline $\begin{array}{l}\text { Gram positive and negative } \\
\text { Gram positive }\end{array}$ & & & & $\begin{array}{l}1 \\
2\end{array}$ \\
\hline Fungal & & & & 2 \\
\hline Subtotals & 6 & 2 & 5 & 19 \\
\hline
\end{tabular}

Identity of the causative organism was confirmed by moderate growth of an organism from the corneal scrapings on one solid medium, growth of the same organism in more than one liquid medium, or growth in one liquid medium that correlated with the Gram stain.

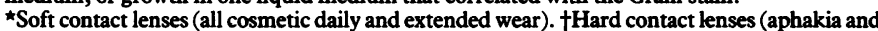
keratoconus, daily wear). $¥$ Therapeutic contact lenses (hard daily and soft extended wear).

keratitis after contamination by "background" levels of Gram negative bacteria that do not affect normal, non-lens users. Interactions between the lens, eye, and bacteria may well be of greater importance in the pathogenesis of keratitis associated with the use of lenses than has been appreciated and might explain some of the apparent differences not explained by contamination of lens cases and solutions alone. ${ }^{5}$

As contact lenses are becoming more common and are the main predisposing factor in microbial keratitis of normal eyes more research into the epidemiology, pathogenesis, and prevention of keratitis is essential. Meanwhile, Gram negative keratitis must be considered in the differential diagnosis of all patients wearing contact lenses who present with an acutely painful red eye. Early diagnosis and treatment are essential to reduce the morbidity in this potentially blinding disease.

I thank the consultant and resident staff at this hospital for facilitating examination of their patients; $M$ Matheson for the microbiological data; $R$ Escott and L Jones for clerical help; and Mr R Buckley, Professor B Jay, and Professor G Woodward for constructive criticism of the manuscript.

1 Coster DJ, Badenoch PR. Host, microbial, and pharmacological factors affecting the outcome of suppurative keratitis. $\mathrm{Br} \mathcal{F}$ Ophthalmol 1987;71:96-101.

2 Alfonso E, Mandelbaum S, Fox MJ, Forster RK. Ulcerative keratitis associated with contact lens wear. Am f Ophthalmol 1986;101:429-33.

3 Hamano H, Kitano J, Mitsunaga S, Kojima S, Kissling GE. Adverse effects of contact lens wear in a large Japanese population. CLAOf 1985;11:141-7.

4 Mayo MS, Cook WL, Schlitzer RL, Ward MA, Wilson LA, Ahearn DG. Antibiograms, serotypes, and plasmid profiles of Pseudomonas aeruginosa associated with corneal uloers and contact lens wear. 3 Clin Microbiol 1986;24:372-6.

5 Dart JKG, Badenoch PR. Bacterial adherence to contact lenses. CLAO J 1986;12:220-4.

(Accepted 30 fuly 1987)

Department of Clinical Ophthalmology, Moorfields Eye Hospital, London ECIV 2PD

J K G DART, MA, FRCs, lecturer in clinical ophthalmology

\section{Tetany induced by frusemide in latent hypoparathyroidism}

Symptomatic hypocalcaemia occurring without a precipitating cause many years after thyroidectomy has been described. ${ }^{1}$ We report on a patient in whom tetany was precipitated 18 years after thyroidectomy by administration of a loop diuretic.

\section{Case report}

An 83 year old woman was admitted with a two week history of gradually increasing dyspnoea, ankle oedema, and orthopnoea. She had undergone a $95 \%$ thyroidectomy 18 years previously for euthyroid nodular colloid goitre. She had become hypocalcaemic within three months after the operation and been treated with oral calciferol for one year. She had subsequently remained asymptomatic.

Before admission she had been taking cyclopenthiazide $500 \mathrm{~g}$ and $8.1 \mathrm{mmo}$ potassium (a sustained release preparation) and thyroxine $0.1 \mathrm{mg}$ a day. On examination her jugular venous pressure was raised. She had bilateral pitting, leg and sacral oedema, inspiratory crackles at both lung bases, and signs of a small right sided pleural effusion. Chest radiographic appearances were compatible with cardiac failure, and there was electrocardiographic evidence of recent myocardial infarction (Q-T interval $0.4 \mathrm{~s}$ at $100 \mathrm{beats} / \mathrm{min}$ ). She was treated with oral frusemide $80 \mathrm{mg}$ and $1.2 \mathrm{~g}$ slow release potassium three times a day. Before treatment plasma urea concentration was $10.2 \mathrm{mmol} / \mathrm{l}$, sodium $139 \mathrm{mmol} / \mathrm{l}$ potassium $3.3 \mathrm{mmol} / \mathrm{l}$, total carbon dioxide $29 \mathrm{mmol} / 1$, creatinine $95 \mathrm{mmol} / \mathrm{l}$ calcium $1.36 \mathrm{mmol} / \mathrm{h}$, phosphate $1.81 \mathrm{mmol} / \mathrm{l}$, and albumin $34 \mathrm{~g} / \mathrm{l}$. Fasting serum parathyroid hormone concentration in the morning 48 hours after admission was undetectable $(<22 \mathrm{mmol} / \mathrm{l})$. The figure shows calcium (corrected) and phosphate concentrations and her drug treatment during her stay in hospital. She had no
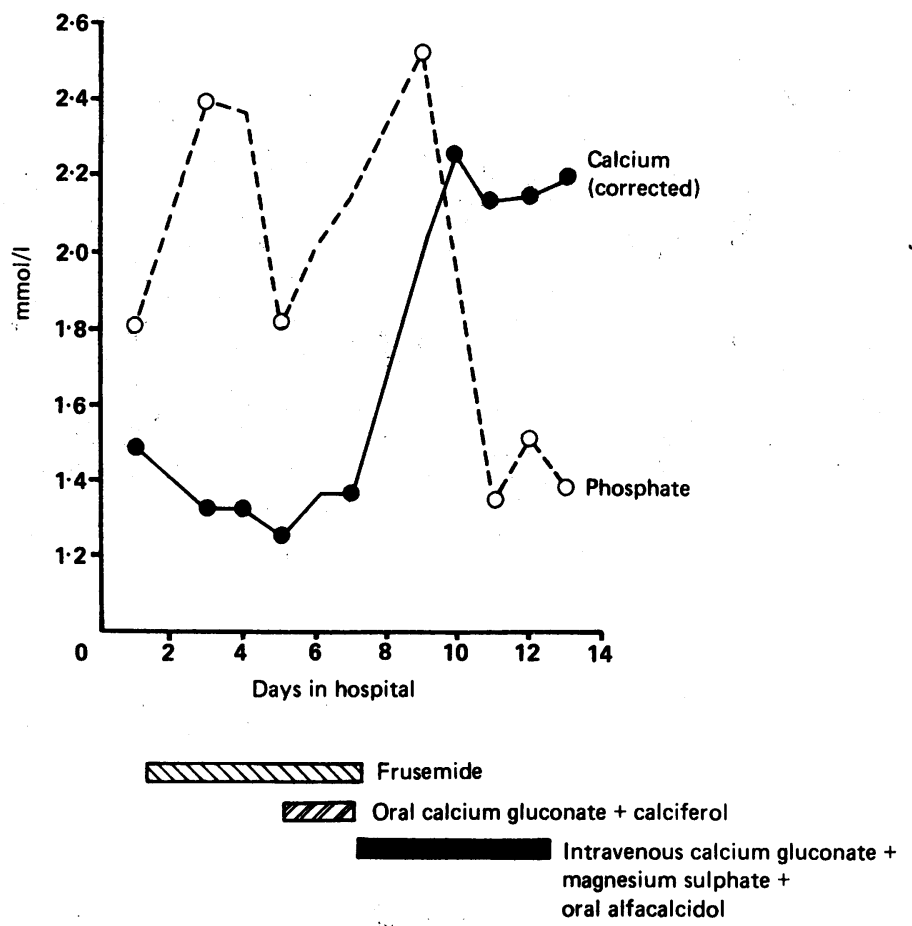

Plasma calcium and phosphate concentrations and drug treatment in patient with latent hypoparathyroidism.

symptoms of hypocalcaemia on admission. Plasma calcium concentration fell during treatment with frusemide, and she developed spasms of her face, generalised twitching of her limbs, and profound confusion. Despite treatment with oral calciferol ( $500 \mu \mathrm{g}$ thrice daily) and effervescent calcium gluconate $(2 \mathrm{~g}$ four times a day, equivalent to $18 \mathrm{mmol}$ calcium) the hypocalcaemia and associated symptoms were refractory, presumably because of the slow onset of action of calciferol. Five days after admission plasma magnesium concentration was low $(0.53 \mathrm{mmol} / 1$; normal range $0.7-1.0 \mathrm{mmol} / 1$ for albumin concentration $34 \mathrm{~g} / \mathrm{l}$ ). Calcium and phosphate concentrations returned to normal with complete resolution of her symptoms only after intravenous replacement with magnesium (60 ml 18\% magnesium sulphate solution over 24 hours) and increased doses of calcium gluconate $(60 \mathrm{ml}$ of a $10 \%$ solution (13.5 mmol calcium a day)) and alfacalcidol ( $1 \mu \mathrm{g}$ twice daily).

Despite the initial improvement she developed pneumonia; Branhamella catarrhalis was isolated from sputum. She failed to respond to clavulanic acid with amoxycillin and died 14 days after admission. Necropsy confirmed the absence of parathyroid tissue.

\section{Comment}

Permanent symptomatic hypoparathyroidism after thyroid surgery occurs in $2 \%$ of patients ${ }^{2}$ and probably results from removal of all parathyroid tissue at operation or from ischaemic damage to the remaining parathyroid tissue. ${ }^{13}$ Many such patients, however, have plasma calcium concentrations in the low normal range, and in response to a low calcium diet and phytates up to $24 \%$ develop hypocalcaemia or symptoms, or both. ${ }^{2}$ There was no clear precipitating factor in the patient, with the longest reported latent period between thyroidectomy and the development of symptomatic hypocalcaemia. ${ }^{1}$ Our patient had asymptomatic hypocalcaemia on admission, which worsened, resulting in tetany when a loop diuretic was given. 
Loop diuretics even in a single dose are associated with increased renal excretion of calcium, potassium, and magnesium. ${ }^{4}$ Hypokalaemia and its associated alkalosis lead to decreased plasma ionised calcium concentrations. Hypomagnesaemia, which is often associated with hypokalaemia, as in our patient, may impair both the secretion of parathyroid hormone and its peripheral action. ${ }^{5}$ Our patient's symptoms were not controlled until magnesium was given parenterally with both calcium gluconate and a rapidly acting vitamin $\mathrm{D}$ preparation.

Loop diuretics can be hazardous in patients with asymptomatic hypoparathyroidism after thyroidectomy. Calcium and magnesium concentrations should be monitored closely during such treatment to avoid depletion of electrolytes and the associated morbidity and mortality.

1 Blanchard BM. Focal hypocalcemic seizures 33 years after thyroidectomy. Arch Intern Med 1962;110:382.

2 Davis RH, Smith JWG, Fourimen A. Prevalence of parathyroid insufficiency after thyroidectomy. Lancet $1961 ; \mathrm{ii}: 1432$.

3 Kaplan EL, Sugimoto J, Yang H, et al. Post-operative hypoparathyroidism: diagnosis and management. In: Kaplan EL, ed. Clinical surgery intemational. Vol 6. Surgery of the thyroid and parathyroid glands. Edinburgh: Churchill Livingstone, 1983:262-74.

4 Suki WN, Yium JJ, von Minden M, et al. Acute treatment of hypercalcemia with furosemide. N Engl\} Med 1970;283:836-40.

5 Rude RK, Oldham SB, Sharp CF, et al. Parathyroid hormone secretion in magnesium deficiency. f Clin Endocrinol Metab 1978;47:800-6.

(Accepted 6 August 1987)

Department of Respiratory Medicine, City Hospital, Edinburgh EH10 5SB ASAD BASHEY, BMSC, MRCP, senior house officer WILLIAM MACNEE, MD, MRCP, senior lecturer

Correspondence to: Dr A Bashey, Department of Haematology, Hammersmith Hospital, London W12 0HS.

\section{Effect of salmon calcitonin on symptoms and urinary excretion of 5 hydroxyindoleacetic acid in the carcinoid syndrome}

Native somatostatin and its long acting analogue SMS 201-995 inhibit symptoms and urinary excretion of 5 hydroxyindoleacetic acid in patients with the carcinoid syndrome. ${ }^{1}$ Calcitonin exerts many effects similar to those of somatostatin on the gastrointestinal tract and pancreas; we studied calcitonin's effect on symptoms and urinary excretion of 5 hydroxyindoleacetic acid in a patient with the carcinoid syndrome and compared its effect with that of somatostatin.

\section{Case report}

A 67 year old woman was admitted with an 18 month history of watery diarrhoea (7-10 bowel movements each day, $600-800 \mathrm{~g}$ stool weight), flushing (two or three times each day), and loss of weight. Examination showed hepatomegaly and a left epigastric mass. Her 24 hour urinary excretion of 5 hydroxyindoleacetic acid was raised (mean $14.5 \mathrm{mg} /$ day, normal 2-10); urinary excretion of serotonin and 5 hydroxytryptophan was normal (figure). Echotomography and computed tomography showed a mass in the pancreatic tail infiltrating the surrounding structures. No hepatic metastases were detected. At operation the mass could not be removed; a biopsy showed "differentiated carcinoid tumour" (confirmed by the Grimelius technique).

For this study the patient was given a $6.3 \mathrm{MJ}(1500 \mathrm{kcal})$ diet ( $20 \%$ protein, $40 \%$ fat, $40 \%$ carbohydrate), and drugs and food rich in serotonin were avoided. On day 3 she received an intravenous infusion of somatostatin $2.5 \mu \mathrm{g} /$ minute for 24 hours. On day 8 she received an intravenous infusion of salmon calcitonin, $8 \mathrm{MRC}$ units/hour for 24 hours. Salmon calcitonin was preferred to human calcitonin because of its greater potency. On days 12,13,14, and 15 salmon calcitonin was given subcutaneously, $100 \mathrm{MRC}$ units every eight hours. Urinary excretion of 5 hydroxyindoleacetic acid and total urinary serotonin and 5 hydroxytryptophan were measured by a chromatographic colorimetric method. The patient gave written, informed consent to the protocol.

With somatostatin the patient's condition improved, with fewer bowel movements (three daily, weight $280 \mathrm{~g} /$ day), relief of cramping abdominal pain, and disappearance of flushes. Her urinary excretion of 5 hydroxyindoleacetic acid fell to $6.6 \mathrm{mg} /$ day; her urinary excretion of serotonin and 5 hydroxytryptophan was unchanged. Mild fasting $(7.9 \mathrm{mmol} / \mathrm{l})$ and postprandial $(10.5 \mathrm{mmol} / \mathrm{l})$ hyperglycaemia was observed without glycosuria. Steatorrhoea developed $(20 \mathrm{~g}$ total faecal fat, normal $<10$ ). When somatostatin was stopped her symptoms and raised urinary concentrations of 5 hydroxyindoleacetic acid recurred promptly. With infusion of salmon calcitonin the patient improved dramatically: bowel movements became less frequent (four daily) and stool weight was less (300 g/day), and her flushing disappeared. She experienced relief of her abdominal pain and a sense of wellbeing not experienced with somatostatin. Her urinary excretion of 5 hydroxyindoleacetic acid fell to $6.1 \mathrm{mg} / \mathrm{day}$; urinary excretion of serotonin and 5 hydroxytryptophan was changed. Neither hyperglycaemia nor steatorrhoea developed. Serum calcium concentration was not affected. After the infusion there was a rebound in symptoms and increased excretion of 5 hydroxyindoleacetic acid. The effects of salmon calcitonin given subcutaneously were similar to those obtained with intravenous infusion.

The patient was still alive one year after the diagnosis and was doing well with treatment with calcitonin.
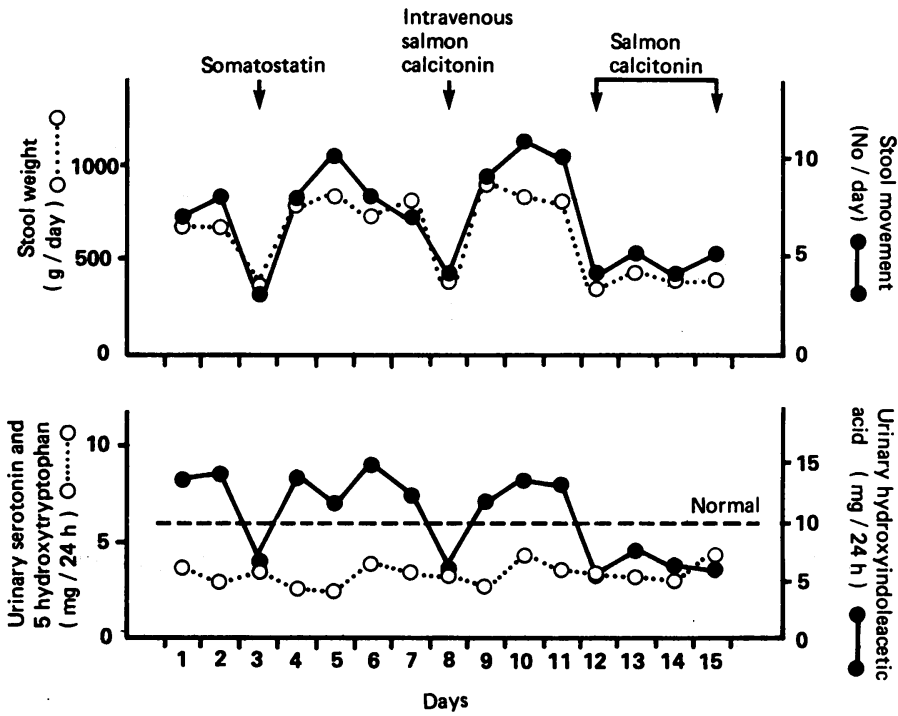

Effect of somatostatin and salmon calcitonin (continuous infusion and subcutaneous injection) on symptoms and biochemical abnormalities in patient with the carcinoid syndrome.

\section{Comment}

These data show that calcitonin mimics somatostatin in reducing clinical symptoms and urinary excretion of 5 hydroxyindoleacetic acid in the carcinoid syndrome. By inhibiting the release of serotonin from carcinoid cells calcitonin may account for some of the marked reductions in her symptoms. Calcitonin had similar effects on symptoms to somatostatin, but it also produced an independent analgesic effect, possibly due to a central neuromodulatory action. ${ }^{2}$ Hyperglycaemia and transient steatorrhoea, commonly associated with somatostatin ${ }^{3}$ were not observed with calcitonin.

Our data suggest that calcitonin may be an alternative to long acting somatostatin analogues in the treatment of the carcinoid syndrome.

1 Oates JA. The carcinoid syndrome. N Engl f Med 1986;315:702-3.

2 Rizzo AJ, Goltzman D. Calcitonin receptors in the central nervous system of the rat. Endocrinology 1981;108:1672-7.

3 Del Pozo E, Neufeld M, Schleuter K, et al. Endocrine profile of a long-acting somatostatin derivative SMS 201-995. Study in normal volunteers following subcutaneous administration. Acta Endocrinol (Copenh) 1986;111:433-9.

(Accepted 30 fuly 1987)

Cattedra di Clinica Medica II, University of Pisa, 67-56 100 Pisa, Italy

ALESSANDRO ANTONELLI, MD, research fellow

PAOLO DEL GUERRA, MD, research fellow

ALESSANDRA FIERABRACCI, $M D$, research fellow

EUGENIO GORI, MD, research fellow

LIDIO BASCHIERI, MD, professor of clinical medicine

Correspondence to: Professor Baschieri.

\section{Correction}

Controlled trial of long term oral potassium supplements in patients with mild hypertension

An authors' error occurred in this paper by Alfonso Siani and others (6 June, p 1453). In table II the $95 \%$ confidence intervals, which read Supine: systolic -8.5 to $-19 \cdot 5$, diastolic -5.9 to $-14 \cdot 1$; Standing: systolic $-4 \cdot 9$ to $-17 \cdot 1$, diastolic $-3 \cdot 6$ to $-11 \cdot 4$, should have read Supine: systolic $-6 \cdot 2$ to $-21 \cdot 8$, diastolic $-4 \cdot 6$ to $-16 \cdot 4$; Standing: systolic $-2 \cdot 6$ to $-19 \cdot 5$, diastolic $-2 \cdot 7$ to $-12 \cdot 1$, respectively. 